\title{
Synthesis and Antimicrobial Activities of a New Class of 6-Arylbenzimidazo[1,2-c]quinazolines
}

\author{
Rondla Rohini, ${ }^{a}$ Kanne Shanker, ${ }^{a}$ P. Muralidhar Reddy ${ }^{b}$ and Vadde Ravinder ${ }^{*, a}$ \\ ${ }^{a}$ Department of Chemistry, Kakatiya University, Warangal-506 009, A.P., India \\ ${ }^{b}$ Department of Chemistry, National Dong Hwa University, Hualien, Taiwan
}

\begin{abstract}
Uma série de compostos 6-arilbenzimidazo[1,2-c]quinazolina (11-20) foram sintetizados pela condensação do 2-(o-aminofenil)benzimidazol com diferentes arilaldeídos seguida pela ciclização oxidativa dos 2- $O$-arilidenoaminofenilbenzimidazol (1-10). Todos os produtos foram caracterizados por espectroscopia no infravermelho (IR), ressonância magnética nuclear de prótons e de carbono, (RMN ${ }^{1} \mathrm{H}$ e RNN ${ }^{13} \mathrm{C}$ ), de massas (MS) e análise elementar. A atividade antimicrobial de todos os 6-arilbenzimidazo[1,2-c]quinazolina foi testada com três linhagens de bactérias Gram-positivas ( $S$. aureus, B. subtilis e S. pyogenes), três Gram-negativas (S. typhimurium, E. coli e K. pneumonia) e de três linhagens de fungos (A. niger, C. albicans e T. viridae). Dos compostos testados, o 13, o 19 e o 20 mostraram-se ser os mais potentes inibidores contra os organismos testados.
\end{abstract}

A series of 6-arylbenzimidazo[1,2-c]quinazoline compounds (11-20) were synthesised by the condensation of 2-(o-aminophenyl)benzimidazole with different arylaldehydes, followed by oxidative cyclisation of the resulting 2-o-arylideneaminophenylbenzimidazoles (1-10). All the products were characterized via IR, ${ }^{1} \mathrm{H}$ NMR, ${ }^{13} \mathrm{C}$ NMR, MS and elemental analysis. The antimicrobial activities of all 6-arylbenzimidazo [1,2-c]quinazolines against three Gram-positive (S. aureus, B. subtilis, S. pyogenes), three Gram-negative (S. typhimurium, E. coli, K. pneumonia) bacteria and three fungal strains (A. niger, C. albicans, T. viridae) were evaluated. Among the compounds tested 13, 19 and $\mathbf{2 0}$ showed most potent inhibitory action against test organisms.

Keywords: 6-Arylbenzimidazo[1,2-c]quinazolines, synthesis, antibacterial activity, antifungal activity

\section{Introduction}

Heterocycles have a central position in medicinal as well as in organic chemistry ${ }^{1-3}$ and considerable attention has been focused on their syntheses. Nitrogen heterocycles in particular exhibit diverse biological and pharmacological activities ${ }^{4-6}$ due in part to the similarities with many natural and synthetic molecules with known biological activity. ${ }^{7}$ Moreover, benzimidazoles and quinazolines are of the most extensively studied classes of heterocyclic compounds, and have received much attention from synthetic organic as well as medicinal chemists, because of the diverse range of their biological activities ${ }^{8,9}$ and their applications in several areas as materials in electronics, in electrochemistry as anticorrosive agents, as polymers or optical materials and fluorescent tags in DNA sequencing. ${ }^{10-12}$ In general,

*e-mail: ravichemku@ rediffmail.com quinazoline compounds have been well-recognized for their pharmacological properties, such as anti-inflammatory, ${ }^{13,14}$ antihypertensive, ${ }^{15}$ anti-HIV,${ }^{16}$ bronco-dilatory, ${ }^{17}$ antiallergic, ${ }^{18}$ anti-cancer, ${ }^{19-21}$ anticonvulsant, ${ }^{22,23}$ antihelmintic, ${ }^{24}$ analgesic, ${ }^{25}$ antimalarial ${ }^{26}$ and antimicrobial ${ }^{27}$ activities. Literature survey reveals that, benzimidazo $[1,2-c]$ quinazoline derivatives also show various biological activities, ${ }^{23,28-30}$ such as anticancer, antiviral, antimicrobial, anti-inflammatory and anticonvulsants. However, search is continuously on to identify a more potent lead molecule as these molecules are developing resistance over a period. Based on the importance of these molecules, our attention was attracted towards synthesis of novel quinazoline derivatives in order to find more potent biologically active molecules. Hence, we report here the synthesis and characterization of new 6-arylbenzimidazo[1,2-c]quinazoline compounds (11-20). In addition, the antimicrobial activities of all synthesized quinazolines against different bacteria and 
fungi were evaluated. Among the compounds tested some of quinazolines were found to be superior in inhibiting all the bacterial and fungal strains.

\section{Results and Discussion}

\section{Chemistry}

The condensation of $o$-phenylenediamine with anthranilic acid was carried out in presence of polyphosphoric acid at $250{ }^{\circ} \mathrm{C}$ for $4 \mathrm{~h}$ to obtain the known 2-(o-aminophenyl) benzimidazole (A) $\left(\mathrm{mp} 214{ }^{\circ} \mathrm{C}\right) .{ }^{31}$ The target compounds were prepared by using the reaction sequence in Scheme 1. Initially, we synthesised ten new 2-o-arylideneaminophenylbenzimidazoles (1-10) via the condensation between 2-(o-aminophenyl benzimidazole(A) and various arylaldehydes. At last, we prepared 6-arylbenzimidazo [1,2-c] quinazolines (11-20) through oxidative cyclisation ${ }^{32}$ of 2-o-arylideneaminophenylbenzimidazoles (1-10).

IR spectra of compound A showed absorption band at $3350 \mathrm{~cm}^{-1}$ assigned to aminophenyl ring and in the case of compounds $\mathbf{A}$ and 1-10 two absorption bands in the region $3150-3300 \mathrm{~cm}^{-1}$ and $1420 \mathrm{~cm}^{-1}$ were assigned to $\mathrm{NH}$ stretching and bending vibrations of imidazolyl ring, respectively. ${ }^{33,34}$ The absence of aminophenyl ring absorption at $3350 \mathrm{~cm}^{-1}$ and appearance of a strong intensity band in the IR spectra of compounds (1-10) in the range of $1610-1650 \mathrm{~cm}^{-1}$ attributable to $\mathrm{v} C=\mathrm{N}$ provides a strong evidence for the condensation and also confirms the formation of the azomethines 1-10. ${ }^{35}$ The oxidative cyclisation of compounds 1-10 to 11-20 were accompanied by the disappearance of the absorption maxima at $3150-3300 \mathrm{~cm}^{-1}$, which are ascribed to the vibrations of $\mathrm{NH}$ group of the benzimidazole ring; at the same time the appearance of a new maximum at $1360-1388 \mathrm{~cm}^{-1}$, which is characteristic for benzimidazoquinazoline ring with a tertiary nitrogen atom, appears. ${ }^{23,36}$

The ${ }^{1} \mathrm{H}$ NMR spectra of the compound $\mathbf{A}$ as well as its derivatives have been recorded in $\mathrm{CDCl}_{3} / \mathrm{DMSO}_{-} \mathrm{d}_{6}$ using TMS as internal standard. In the spectra of 2 -(o-aminophenyl) benzimidazole (A), signals at $\delta 6.4$ and $\delta 8.25 \mathrm{ppm}$ were appeared corresponding to free amino and imidazolyl protons respectively. ${ }^{33,35}$ The aromatic protons of various environments present in all compounds appeared as multiplets in the range of $\delta 6.84-8.81 \mathrm{ppm} .{ }^{35,37}$ ${ }^{1} \mathrm{H}$ NMR spectra of compounds 1-10 contain signals corresponding to $\mathrm{CH}=\mathrm{N}$ protons in the range of $\delta 8.07$ $8.29 \mathrm{ppm}$ suggesting the condensation of aromatic aldehydes with compound $\mathbf{A}$. However, in the spectra of 1-10 compounds the disappearance of signals at $\delta 6.4 \mathrm{ppm}$ which is due to $\mathrm{NH}_{2}$ protons of compound $\mathbf{A}$ supports the involvement of amino group in condensation and confirms the formation of azomethines. Finally, in the spectra of 11-20 compounds disappearance of signals corresponding to $-\mathrm{NH}$ of imidazolyl ring and $\mathrm{CH}=\mathrm{N}$ protons supports the benzimidazoquinazoline ring structure..$^{23,36}$

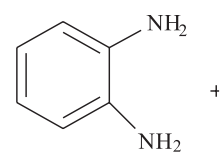

Orthophenylenediamine<smiles>Nc1ccccc1C(=O)O</smiles>

Anthranillic acid

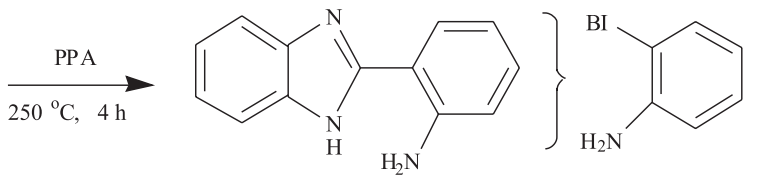

2-(o-Aminoph en yl)b en zimid azole(A)

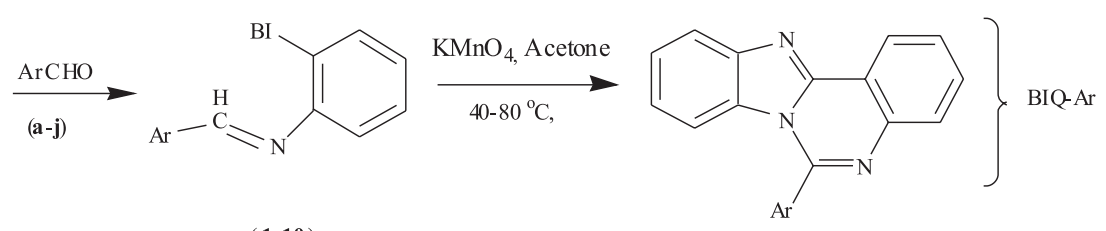

(1-10)

$$
\begin{aligned}
& \mathbf{a}=2 \text {-Hydroxy-benzaldehyde } \\
& \mathbf{b}=5 \text {-Brom o-2-hydroxy-benzaldehyde } \\
& \mathbf{c}=2 \text {-Hydroxy-5-nitro-benzalde hyde } \\
& \mathbf{d}=2 \text {-Hydroxy-5-methoxy-be nz ald ehy de } \\
& \mathbf{e}=3 \text {-Formyl-benzoic acid }
\end{aligned}
$$

(11-20)

$\mathbf{f}=3$-Formyl-4-hydroxy-be nzoic a cid

g = 4-Hydroxy-3,5-dimethyl-benzaldehyde

$\mathbf{h}=3,5$-Dimethoxy-be nza ldehyde

$\mathbf{i}=$ Quinoline-2-carbaldehyde

$\mathbf{j}=$ Pyridine-3 - ca rbaldehyde 
${ }^{13} \mathrm{C}$ NMR spectra of all the compounds contain signals in the range of $\delta 141.1-171.2 \mathrm{ppm}$ confirming the presence of carbon, which is doubly bonded to nitrogen. The aromatic carbons of various environments present in all the compounds appeared as signals in the range of $\delta$ 103.2-156.2 ppm. ${ }^{37}$ The ${ }^{1} \mathrm{H}$ and ${ }^{13} \mathrm{C}$ NMR spectra (Figure S2 and Figure S3) of compound $\mathbf{2 0}$ are given in supplementary material.

All the compounds (except $\mathbf{2}$ and 12) showed a single peak in ESI-MS suggesting the molecular formulae of the azomethines and quinazolines. Compounds, $\mathbf{2}$ and $\mathbf{1 2}$ exhibited molecular ion peaks $\left(\mathbf{M}^{+}\right)$at $m / z 391,\left(\mathbf{M}^{+2}\right)$ at $\mathrm{m} / \mathrm{z} 393$ and $\left(\mathbf{M}^{+}\right)$at $m / z 389,\left(\mathbf{M}^{+2}\right)$ at $m / z 391$ respectively, which is due to the isotopic abundance of bromine. The FAB mass spectrum of compound $\mathbf{2 0}$ shows a molecular ion peak $\left(\mathbf{M}^{+}\right)$at $m / z 296(65.1 \%)$, which confirms the proposed formula $\left(\mathrm{C}_{19} \mathrm{H}_{12} \mathrm{~N}_{4}\right)$. The peaks have been observed at $\mathrm{m} / \mathrm{z}$ values $218(40.3 \%), 193(52.2 \%), 192(100 \%), 180(74.8 \%)$ and $76(24.4 \%)$, which indicate the fragmentation pattern and their intensity gives an idea about the abundance and stability of the fragments. The mass fragmentation pattern (Scheme S1) of compound $\mathbf{2 0}$ as assigned on the basis of mass spectra (Figure S3) is presented in supplementary material.

\section{Biological study}

\section{Antimicrobial activity}

The in vitro antimicrobial activity was carried out by cupplate method. ${ }^{38} \mathrm{All}$ the synthesized quinazolines were screened for antibacterial activity against Staphylococcus aureus,
Bacillus subtilis, Streptococcus pyogenes (Gram positive) and Salmonella typhimurium, Escherichia coli, Klebsiella pneumonia (Gram negative) bacterial strains using ampicillin as standard. The antifungal activity was investigated against Aspergillus niger, Candida albicans, Trichoderma viridae fungal strains using ketoconazole as standard. Preliminary screening of target compounds and standard drugs were performed at fixed concentrations of $1000 \mu \mathrm{g} \mathrm{mL}{ }^{-1}$. Inhibition was recorded by measuring the diameter of the inhibition zone at the end of $48 \mathrm{~h}$ for bacteria and $72 \mathrm{~h}$ for fungi. Each experiment was repeated thrice and the average of the three independent determinations was recorded. Screening results are summarized in Table 1. Among the compounds tested $\mathbf{1 3}$ was found to exhibit good activity against all bacterial and fungal strains. Furthermore, the most potent activity was observed in $\mathbf{1 9}$ and $\mathbf{2 0}$ against all bacterial and fungal strains when compared to respective standard drugs ampicillin and ketoconazole. The minimum inhibitory concentration ${ }^{39}$ of these quinazolines $(\mathbf{1 3}, 19$ and 20) was also verified by the liquid dilution method in which the effectiveness was observed at lower concentrations. The detailed antibacterial and antifungal preliminary screening methods are given in supplementary material.

Determination of minimum inhibitory concentration (MIC)

The minimum inhibitory concentration of $\mathbf{1 3}, \mathbf{1 9}$ and $\mathbf{2 0}$ against $S$. aureus, B. subtilis, S. pyogenes, S. typhimurium, E. coli, K. pneumonia (bacterial strains), Aspergillus niger, Candida albicans, Trichoderma viridae (fungal strains) were determined by liquid dilution method. Stock solutions of test samples with $2.5,5,10,15,20,25,30$,

Table 1. Zone of inhibition of newly synthesized 6-arylbenzimidazo[1,2-c]quinazolines (11-20) against different bacteria and fungi

\begin{tabular}{|c|c|c|c|c|c|c|c|c|c|}
\hline \multirow{3}{*}{$\begin{array}{l}\text { Compound } \\
\left(1000 \mu \mathrm{g} \mathrm{m}^{-1}\right)\end{array}$} & \multicolumn{9}{|c|}{ Zone of inhibition (mm) } \\
\hline & \multicolumn{3}{|c|}{ Gram-positive bacteria } & \multicolumn{3}{|c|}{ Gram-negative bacteria } & \multicolumn{3}{|c|}{ Fungi } \\
\hline & S. aureus & B. subtilis & S. pyogenes & S. typhimurium & E. coli & K. pneumonia & A. niger & C. albicans & T. viridae \\
\hline 11 & 20 & 18 & 13 & 15 & 18 & 16 & 21 & 16 & 9 \\
\hline 12 & 21 & 20 & 15 & 15 & 19 & 18 & 18 & 15 & 12 \\
\hline 13 & 50 & 45 & 48 & 45 & 48 & 50 & 49 & 48 & 46 \\
\hline 14 & 19 & 14 & 15 & 12 & 21 & 15 & 16 & 13 & 13 \\
\hline 15 & 22 & 18 & 13 & 16 & 18 & 12 & 15 & 10 & 9 \\
\hline 16 & 18 & 14 & 15 & 12 & 20 & 16 & 16 & 12 & 13 \\
\hline 17 & 16 & 18 & 15 & 15 & 19 & 18 & 18 & 15 & 12 \\
\hline 18 & 15 & 10 & 12 & 10 & 9 & 13 & 11 & 9 & 13 \\
\hline 19 & 55 & 45 & 52 & 50 & 50 & 52 & 55 & 50 & 50 \\
\hline 20 & 52 & 48 & 50 & 46 & 51 & 50 & 50 & 51 & 48 \\
\hline Std & $48^{\mathrm{a}}$ & $39^{\mathrm{a}}$ & $35^{\mathrm{a}}$ & $45^{\mathrm{a}}$ & $40^{\mathrm{a}}$ & $45^{\mathrm{a}}$ & $45^{\mathrm{b}}$ & $40^{\mathrm{b}}$ & $41^{\mathrm{b}}$ \\
\hline
\end{tabular}

${ }^{\mathrm{a}}$ Ampicillin; ${ }^{\mathrm{b}}$ Ketoconazole 
$35,40,45$ and $50 \mu \mathrm{g} \mathrm{mL}-1$ concentrations were prepared with appropriate solvent. The solutions of standard drugs, ampicillin and ketoconazole were prepared in the same concentrations. Inoculums of the bacterial and fungal culture were also prepared. To a series of tubes containing $1 \mathrm{~mL}$ each of quinazoline compound solution with different concentrations and $0.2 \mathrm{~mL}$ of the inoculum was added. Further $3.8 \mathrm{~mL}$ of the sterile water was added to each of the test tubes. These test tubes were incubated for $24 \mathrm{~h}$ and observed for the presence of turbidity. This method was repeated by changing quinazoline compounds with standard drug ampicillin (in case of bacteria) and with ketoconazole (in case of fungi) for comparison. The minimum inhibitory concentration at which no growth was observed was taken as the MIC values. Comparison of MIC values (in $\mu \mathrm{g} \mathrm{mL}^{-1}$ ) of quinazolines and standard drugs against different bacteria and fungi are presented in Figure 1. From these results, it is evident that $\mathbf{1 3}$ (MIC range 5-20 $\mu \mathrm{g} \mathrm{mL}^{-1}$ ), 19 and 20 compounds (MIC range 2.5-15 $\mu \mathrm{g} \mathrm{mL}^{-1}$ ) are showing superior activity when compared to ampicillin and ketoconazole towards inhibiting all tested bacterial and fungal strains.

\section{Conclusions}

Quinazolines and related derivatives are classes of heterocyclic compounds contain the pyrimidine nucleus in their structures. Literature survey reveals that a variety of antimicrobial agents contains quinazoline moiety and also fused quinazoline ring systems such as benzimidazoloquinazolines, indoloquinazolines and many other. In a search for new fused quinazoline systems with potential biological activities, we planned to prepare new 6-arylbenzimidazo[1,2-c]quinazolines, from 2-(o-aminophenyl) benzimidazole and various aldehydes as starting compounds. We have chosen six bacterial and three fungal strains for microbial studies of these entire quinazoline compounds. From this study it is evident that all quinazoline compounds are showing moderate to good activity towards inhibiting all tested bacterial

Table 2 . MIC values potent 6-arylbenzimidazo[1,2-c]quinazolines (13, 19 and 20) and standard drugs

\begin{tabular}{|c|c|c|c|c|c|c|c|c|c|}
\hline \multirow[t]{3}{*}{ Compound } & \multicolumn{9}{|c|}{ Range of concentration $\left(\mu \mathrm{g} \mathrm{mL}^{-1}\right)$} \\
\hline & \multicolumn{3}{|c|}{ Gram-positive bacteria } & \multicolumn{3}{|c|}{ Gram-negative bacteria } & \multicolumn{3}{|c|}{ Fungi } \\
\hline & S.aureus & B. subtilis & S. pyogenes & S. typhimurium & E. coli & K. pneumonia & A. niger & C. albicans & T. viridae \\
\hline 13 & 10 & 15 & 20 & 10 & 15 & 5 & 10 & 20 & 15 \\
\hline 19 & 2.5 & 15 & 10 & 5 & 10 & 2.5 & 2.5 & 5 & 10 \\
\hline 20 & 5 & 10 & 15 & 10 & 10 & 5 & 10 & 15 & 15 \\
\hline Std & $10^{\mathrm{a}}$ & $20^{\mathrm{a}}$ & $25^{\mathrm{a}}$ & $10^{\mathrm{a}}$ & $15^{\mathrm{a}}$ & $10^{\mathrm{a}}$ & $15^{\mathrm{b}}$ & $25^{\mathrm{b}}$ & $20^{\mathrm{b}}$ \\
\hline
\end{tabular}

${ }^{\mathrm{a}}$ Ampicillin; ${ }^{\mathrm{b}}$ Ketoconazole

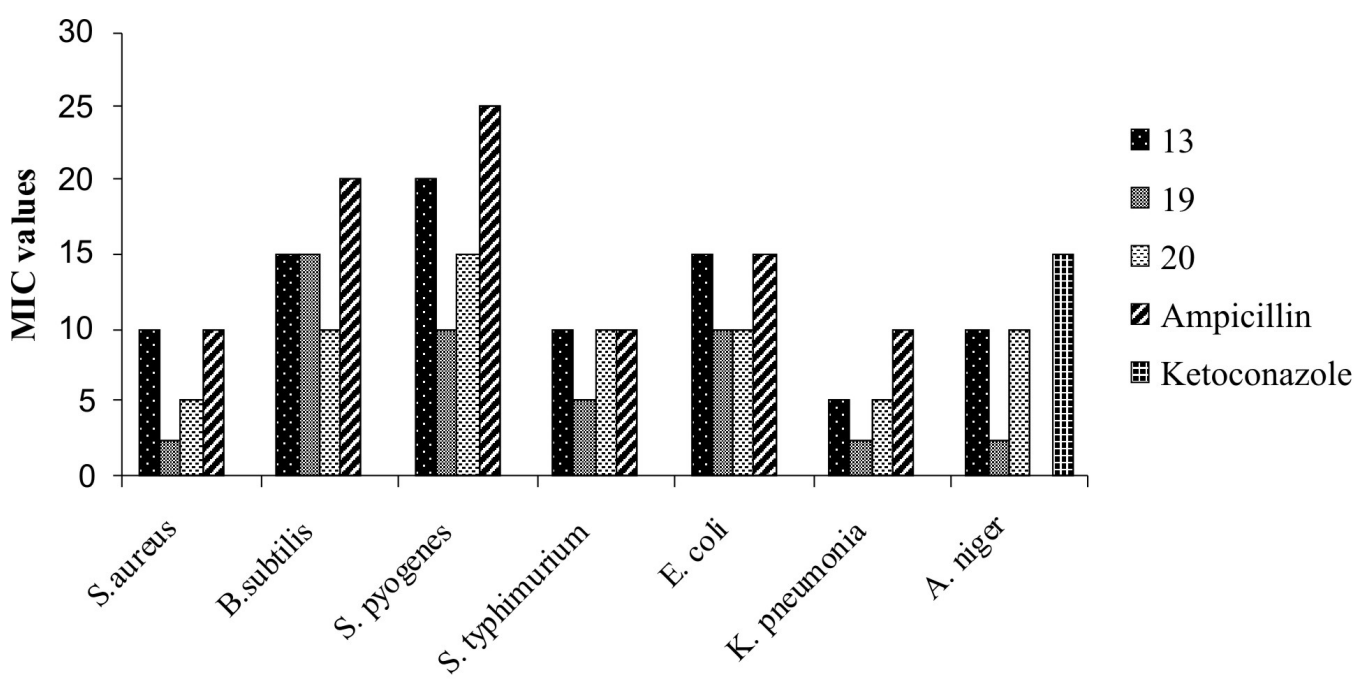

Bacteria and Fungi

Figure 1. Comparison of MIC values (in $\mu \mathrm{g} \mathrm{mL}^{-1}$ ) of quinazolines and standard drugs against different bacteria and fungi. 
and fungal strains. Furthermore, the most potent activity was observed in (13, 19 and 20) against all bacterial and fungal strains when compared to respective standard drugs ampicillin and ketoconazole. A possible explanation for this result is that the biological activity of compounds may be depending on the basic skeleton of molecule as well as on the nature of substituents. Hence we conclude that the most potent activity of $\mathbf{1 3 , 1 9}$ and $\mathbf{2 0}$ compounds may be due to the presence of heterocyclic isoquinolyl, pyridyl and nitro substituted aryl groups at $\mathrm{C}_{6}$ position of the benzimidazo[1,2-c]quinazoline moiety.

\section{Experimental}

Analar grade reagents and freshly distilled solvents were used throughout the investigations. Compounds were checked for their purity by TLC using Merck $60 \mathrm{~F}_{254}$ silica gel plates and spots were located by iodine vapors. Micro analytical (C, $\mathrm{N}, \mathrm{H}$ ) data was obtained by using a Perkin-Elmer $2400 \mathrm{CHN}$ elemental analyzer. The IR spectra were recorded in $\mathrm{KBr}$ pellets on Perkin-Elmer-283 spectrophotometer. ${ }^{1} \mathrm{H}$ NMR spectra were acquired at $400 \mathrm{MHz}$ and ${ }^{13} \mathrm{C} \mathrm{NMR}$ was acquired at $67.93 \mathrm{MHz}$ on a Bruker NMR spectrometer. FAB mass spectra were recorded on a Finnigan-MAT 1020 instrument. An ion trap mass spectrometer (Agilent Series LC/MSD Trap SL) equipped with an electrospray ionization (ESI) source was used for MS analyses. Hot air oven (Instrument and Equipment Pvt. Ltd., Mumbai), incubator (Instrument and Equipment Pvt. Ltd., Mumbai), laminar airflow unit (Clas laminar technologies Pvt. Ltd. Secunderabad), autoclave (Medica Instrument Mfg. Co., Mumbai) were used in the present investigations. Organisms like Staphylococcus aureus, Bacillus subtilis, Streptococcus pyogenes (Gram positive), Salmonella typhimurium, Escherichia coli, Klebsiella pneumonia (Gram negative) bacteria and Aspergillus niger, Candida albicans, Trichoderma viridae fungi were used in the present investigations.

Preparation of 2-(o-aminophenyl)benzimidazole [BIPhNH ${ }_{2}$ ] (A)

2-(o-aminophenyl) benzimidazole (A) was prepared by reacting orthophenylenediamine (OPD) with anthranillic acid in freshly prepared polyphosphoric acid (PPA) acid at $250{ }^{\circ} \mathrm{C}$ for $4 \mathrm{~h}$.

Procedure for preparation of mono-2-o-(arylideneamino) phenyl benzimidazoles (1-10)

To a hot stirred solution of 2-(o-aminophenyl) benzimidazole (A) $(2 \mathrm{mmol})$ in ethanol $(20 \mathrm{~mL})$ were added the appropriate aldehyde $(2 \mathrm{mmol})$ and 2-3 drops of acetic acid. The resultant mixture was refluxed under heat $\left(40-55^{\circ} \mathrm{C}\right)$ for $2 \mathrm{~h}$ after which the compound was obtained. The product was filtered and recrystalized from a dichloromethane-methanol mixture.

Procedure for preparation of 6-arylbenzimidazo[1,2-c] quinazolines[BIQ-Ar] (11-20)

All the 6-arylbenzimidazo[1,2-c]quinazolines (11-20) were prepared from azomethines 1-10 through oxidative cyclisation method reported by Davis and Mann. ${ }^{32}$ Powdered potassium permanganate ( 1.5 equiv.) was added to a solution of the azomethyne compound (1-10) in $50-75 \mathrm{~mL}$ of acetone. The mixture was boiled $\left(40-80{ }^{\circ} \mathrm{C}\right)$ under reflux for $30 \mathrm{~min}$. It was then filtered hot, and an equal volume of hot water added to the filtrate. The quinazolines (11-20) rapidly separated, and was collected by filtration and recrystalized from dimethylformamide. All the synthesized compounds were characterized as given below.

\section{2-(o-Aminophenyl)benzimidazole [BIPhNH $\left.{ }_{2}\right](\boldsymbol{A})$}

Yield 82\%; mp 213-214 ${ }^{\circ} \mathrm{C}$ (lit. 214 ${ }^{\circ} \mathrm{C}$ ); ${ }^{31} \mathrm{IR} \mathrm{v}_{\max } / \mathrm{cm}^{-1}$ : $3350\left(\mathrm{NH}_{2}\right), 3300(\mathrm{NH}) ;{ }^{1} \mathrm{H}$ NMR $\left(400 \mathrm{MHz}, \mathrm{CDCl}_{3}\right) \delta$ 6.4 (s, 2H, $\mathrm{NH}_{2}$ ), 6.5-7.7 (m, 8H, Ar-H), 8.25 (s, 1H, NH); ${ }^{13} \mathrm{C}$ NMR $\left(67.93 \mathrm{MHz}, \mathrm{CDCl}_{3}\right) \delta 113.1,114.2,116.2,119.3$, 121.5, 123.2, 130.3, 141.5. 145.2, 154.1 (13C, Ar-C). Anal. Found: C, 74.65; H, 5.32; N, 20.05. Calc. for $\mathrm{C}_{13} \mathrm{H}_{11} \mathrm{~N}_{3}$ : C, 74.62; H, 5.30; N, 20.08\%. MS (ESI): $\left(\mathrm{M}^{+}\right) \mathrm{m} / \mathrm{z}$ at 209.

\section{2-([2-(1H-Benzo[d]imidazol-2-yl)phenyl]iminomethyl)} phenol (1)

Yield 81\%; mp 288-290 ${ }^{\circ} \mathrm{C}$; IR $v_{\max } / \mathrm{cm}^{-1}: 3420,3300$, $1650,1590,1575,1130 ;{ }^{1} \mathrm{H}$ NMR (400 MHz, $\left.\mathrm{CDCl}_{3}\right) \delta 6.83$ (t, $1 \mathrm{H}, \mathrm{Ar}, J$ 7.4Hz), 6.95-7.38 (m, 9H, Ar), 7.63-7.95 (m, $2 \mathrm{H}, \mathrm{Ar}), 8.25(\mathrm{~s}, 1 \mathrm{H}, \mathrm{CH}=\mathrm{N}), 8.89$ (s, 1H, imidazolyl-NH) 10.22 (s, $1 \mathrm{H},-\mathrm{OH}) ;{ }^{13} \mathrm{C} \mathrm{NMR}\left(67.93 \mathrm{MHz}, \mathrm{CDCl}_{3}\right) \delta 114.3$, $117.2,118.4,123.5,126.4,131.5,132.2,133.6,136.5$, 141.2, 142,6, 143.8, 146.3, 163.7, 167.5 (20C, Ar-C); Anal. Found: C, 76.65; H, 4.81; N, 13.40. Calc. for $\mathrm{C}_{20} \mathrm{H}_{15} \mathrm{~N}_{3} \mathrm{O}$ : C, 76.66; H, 4.82; N, 13.41\%. MS (ESI): $\left(\mathrm{M}^{+}\right) \mathrm{m} / \mathrm{z}$ at 313.

2-([2-(1H-Benzo[d]imidazol-2-yl)phenyl]iminomethyl)-4bromophenol (2)

Yield 79\%; mp 318-320 ${ }^{\circ} \mathrm{C}$; IR $v_{\max } / \mathrm{cm}^{-1}: 3425,3300$, $1630,1610,1580,1100 ;{ }^{1} \mathrm{H}$ NMR (400 MHz, $\left.\mathrm{CDCl}_{3}\right) \delta 6.82$ (t, $1 \mathrm{H}, \mathrm{Ar}, J 7.4 \mathrm{~Hz}), 6.85(\mathrm{~S}, 1 \mathrm{H}, \mathrm{Ar}), 6.92-7.46(\mathrm{~m}, 7 \mathrm{H}, \mathrm{Ar})$, $7.62-7.94(\mathrm{~m}, 2 \mathrm{H}, \mathrm{Ar}), 8.21(\mathrm{~s}, 1 \mathrm{H}, \mathrm{CH}=\mathrm{N}), 8.86(\mathrm{~s}, 1 \mathrm{H}$, -NH), 10.21 (s, $1 \mathrm{H},-\mathrm{OH}) ;{ }^{13} \mathrm{C}$ NMR $\left(67.93 \mathrm{MHz}, \mathrm{CDCl}_{3}\right)$ $\delta$ 107.5, 114.1, 118.2, 123.5, 126.2, 130.5, 131.2, 132.2, $136.5,141.1,142,8,143.5,146.3,154.48,158.5,167.1$ 
(20C, Ar-C); Anal. Found: C, 61.20; H, 3.56; N, 10.71. Calc. for $\mathrm{C}_{20} \mathrm{H}_{14} \mathrm{BrN}_{3} \mathrm{O}: \mathrm{C}, 61.24 ; \mathrm{H}, 3.60 ; \mathrm{N}, 10.71 \%$. MS (ESI): $\left(\mathbf{M}^{+}\right) \mathrm{m} / \mathrm{z}(\%) 391,\left(\mathbf{M}^{+2}\right) \mathrm{m} / \mathrm{z}$ at 393.

\section{2-([2-(1H-Benzo[d]imidazol-2-yl)phenyl]iminomethyl)-} 4-nitrophenol (3)

Yield $81 \%$; mp $255-257^{\circ} \mathrm{C}$; IR $v_{\max } / \mathrm{cm}^{-1}: 3420,3300$, $1635,1608,1590,1525,1345,1130,850 ;{ }^{1} \mathrm{H}$ NMR $\left(400 \mathrm{MHz}, \mathrm{CDCl}_{3}\right) \delta 6.82(\mathrm{t}, 1 \mathrm{H}, \mathrm{Ar}, J 7.4 \mathrm{~Hz}), 7.05-7.41(\mathrm{~m}$, $6 \mathrm{H}, \mathrm{Ar}), 7.60(\mathrm{~s}, 1 \mathrm{H}, \mathrm{Ar}), 7.63-7.95(\mathrm{~m}, 2 \mathrm{H}, \mathrm{Ar}), 8.01(\mathrm{~d}, 1 \mathrm{H}$, $J 7.7 \mathrm{~Hz}), 8.29(\mathrm{~s}, 1 \mathrm{H}, \mathrm{CH}=\mathrm{N}), 8.85(\mathrm{~s}, 1 \mathrm{H},-\mathrm{NH}), 10.45(\mathrm{~s}$, $1 \mathrm{H},-\mathrm{OH}) ;{ }^{13} \mathrm{C}$ NMR $\left(67.93 \mathrm{MHz}, \mathrm{CDCl}_{3}\right) \delta 114.4,118.1$, $119.2,123.1,124.3,126.2,131.2,132.2,136.5,141.1$, 143.5, 146.5, 164.8, 170.2 (20C, Ar-C); Anal. Found: C, 67.01; H, 3.95; N, 15.58. Calc. for $\mathrm{C}_{20} \mathrm{H}_{14} \mathrm{~N}_{4} \mathrm{O}_{3}: \mathrm{C}, 67.03$; $\mathrm{H}, 3.94 ; \mathrm{N}, 15.63 \%$. MS (ESI): $\left(\mathrm{M}^{+}\right) \mathrm{m} / z$ at 358 .

2-([2-(1H-Benzo[d]imidazol-2-yl)phenyl]iminomethyl)-4methoxyphenol (4)

Yield 80\%; mp $285-287^{\circ} \mathrm{C}$; IR $v_{\max } / \mathrm{cm}^{-1}: 3425,3300$, $1638,1605,1585,1246,1128,1035 ;{ }^{1} \mathrm{H}$ NMR $(400 \mathrm{MHz}$, $\left.\mathrm{CDCl}_{3}\right) \delta 3.90\left(\mathrm{~s}, 3 \mathrm{H}, \mathrm{OCH}_{3}\right), 6.48(\mathrm{~s}, 1 \mathrm{H}, \mathrm{Ar}), 6.83(\mathrm{t}, 1 \mathrm{H}$, Ar, J 7.4 Hz), 6.84-7.65 (m, 8H, Ar), 7.94 (d, 1H, Ar, J 7.3 $\mathrm{Hz}), 8.16$ (s, 1H, CH=N), 8.85 (s, 1H, -NH), $10.22(\mathrm{~s}, 1 \mathrm{H}$, $-\mathrm{OH}) ;{ }^{13} \mathrm{C} \mathrm{NMR}\left(67.93 \mathrm{MHz}, \mathrm{CDCl}_{3}\right) \delta 56.1,\left(1 \mathrm{C},-\mathrm{OCH}_{3}\right)$, $114.0,121.5,122.4,123.5,126.2,130.5,131.1,132.4$, 141.1, 142,3, 146.8, 153.2, 153.6, 167.5 (20C, Ar-C), Anal. Found: C, 73.42; $\mathrm{H}, 5.01 ; \mathrm{N}, 12.25$. Calc.for $\mathrm{C}_{21} \mathrm{H}_{17} \mathrm{~N}_{3} \mathrm{O}_{2}$ : C, $73.45 ; \mathrm{H}, 4.99 ; \mathrm{N}, 12.24 \%$. MS (ESI): $\left(\mathrm{M}^{+}\right)$at $\mathrm{m} / z 343$.

\section{3-([2-(1H-Benzo[d]imidazol-2-yl)phenyl]iminomethyl $)$} benzoic acid (5)

Yield 76\%; mp 226-228 ${ }^{\circ} \mathrm{C}$; IR $v_{\max } / \mathrm{cm}^{-1}: 3535,3300$, $3215,1685,1635,1580,1130 ;{ }^{1} \mathrm{H} N M R\left(400 \mathrm{MHz}, \mathrm{CDCl}_{3}\right)$ $\delta 6.83$ (t, 1H, Ar, J 7.4 Hz), 7.05-8.20 (m, 12H, Ar), 8.82 (s, 1H, -NH), 11.31 (s, 1H, -COOH); ${ }^{13} \mathrm{C}$ NMR (67.93 $\mathrm{MHz}, \mathrm{CDCl}_{3}$ ) $\delta 114.1,114.4,123.5,126.2,129.2,130.5$, $130.8,132.0,133.1,141.1,143.5,146.8,167.1,170.2$ (21C, Ar-C), Anal. Found: C, 73.85; H, 4.49; N, 12.32 . Calc. for $\mathrm{C}_{21} \mathrm{H}_{15} \mathrm{~N}_{3} \mathrm{O}_{2}$ : C, 73.89; $\mathrm{H}, 4.43 ; \mathrm{N}, 12.31 \%$. MS (ESI): $\left(\mathbf{M}^{+}\right)$at $m / z, 341$.

3-([2-(1H-Benzo[d]imidazol-2-yl)phenyl]iminomethyl)-4hydroxybenzoic acid (6)

Yield 79\%; mp 315-317 ${ }^{\circ} \mathrm{C}$; IR $v_{\max } / \mathrm{cm}^{-1}: 3535,3425$, $3300,3215,1680,1640,1585,1128 ;{ }^{1} \mathrm{H}$ NMR $(400 \mathrm{MHz}$, $\left.\mathrm{CDCl}_{3}\right) \delta 6.83(\mathrm{t}, 1 \mathrm{H}, \mathrm{Ar}, J 7.4 \mathrm{~Hz}), 7.02-8.13(\mathrm{~m}, 11 \mathrm{H}$, Ar), 8.89 (s, 1H, -NH), $10.21(\mathrm{~s}, 1 \mathrm{H},-\mathrm{OH}), 11.42(\mathrm{~s}, 1 \mathrm{H}$, $-\mathrm{COOH}) ;{ }^{13} \mathrm{C}$ NMR $\left(67.93 \mathrm{MHz}, \mathrm{CDCl}_{3}\right) \delta 113.6,114.0$, $114.3,123.4,124.5,126.2,127.5,132.8,136.4,141.1$, 142,3, 144.5, 146.1, 166.2, 166.7, 168.8 (21C, Ar-C); Anal.
Found: C, 70.60; H, 4.25; N, 11.70. Calc. for $\mathrm{C}_{21} \mathrm{H}_{15} \mathrm{~N}_{3} \mathrm{O}_{3}$ : C, $70.58 ; \mathrm{H}, 4.23 ; \mathrm{N}, 11.76 \%$. MS (ESI): $\left(\mathrm{M}^{+}\right)$at $m / z 357$.

4-([2-(1H-Benzo[d]imidazol-2-yl)phenyl]iminomethyl)2,6-dimethylphenol (7)

Yield 78\%; mp 211-213 ${ }^{\circ} \mathrm{C}$; IR $v_{\max } / \mathrm{cm}^{-1}: 3425,3300$, 2958, 1645, 1608, 1575, 1130; ${ }^{1} \mathrm{H}$ NMR (400MHz, $\mathrm{CDCl}_{3}$ ) $\delta 2.30\left(\mathrm{~s}, 6 \mathrm{H}, \mathrm{Ar}-\mathrm{CH}_{3}\right), 6.61(\mathrm{~S}, 2 \mathrm{H}, \mathrm{Ar}), 6.83(\mathrm{t}, 1 \mathrm{H}, \mathrm{Ar}$, $J 7.4 \mathrm{~Hz}$ ), 7.06-7.41 (m, 5H, Ar), $7.62-7.93$ (m, 2H, Ar), $8.07(\mathrm{~s}, 1 \mathrm{H}, \mathrm{CH}=\mathrm{N}), 8.85(\mathrm{~s}, 1 \mathrm{H},-\mathrm{NH}), 10.21(\mathrm{~s}, 1 \mathrm{H}$, $-\mathrm{OH}) ;{ }^{13} \mathrm{C}$ NMR $\left(67.93 \mathrm{MHz}, \mathrm{CDCl}_{3}\right) \delta 15.7(2 \mathrm{C},-\mathrm{CH} 3)$, 114.1, 123.4, 126.2, 127.4, 128.3, 132.2, 136.3, 141.1, 146.6, 152.8, 171.2 (20C, Ar-C); Anal. Found: C, 77.44; $\mathrm{H}, 5.60 ; \mathrm{N}, 12.29$. Calc. for $\mathrm{C}_{22} \mathrm{H}_{19} \mathrm{~N}_{3} \mathrm{O}: \mathrm{C}, 77.40 ; \mathrm{H}, 5.61$; N, 12.31\%. MS (ESI): $\left(\mathrm{M}^{+}\right)$at $m / z 341$.

N1-[(E)-1-(3,5-Dimethoxyphenyl)methylidene $-2-(1 H-$ benzo[d]imidazol-2-yl) aniline (8)

Yield 75\%; mp 228-230 ${ }^{\circ} \mathrm{C}$; IR $v_{\max } / \mathrm{cm}^{-1}: 3300,1635$, 1600, 1580, 1246,1130, 1035; ${ }^{1} \mathrm{H}$ NMR (400 MHz, $\mathrm{CDCl}_{3}$ ) $\delta 3.90\left(\mathrm{~s}, 6 \mathrm{H},-\mathrm{OCH}_{3}\right), 6.46(\mathrm{~S}, 1 \mathrm{H}, \mathrm{Ar}), 6.82(\mathrm{t}, 1 \mathrm{H}, \mathrm{Ar}$, J $7.4 \mathrm{~Hz}$ ), 6.85 (S, 2H, Ar), 7.08-7.45 (m, 5H, Ar), 7.62$7.94(\mathrm{~m}, 2 \mathrm{H}, \mathrm{Ar}), 8.14(\mathrm{~s}, 1 \mathrm{H}, \mathrm{CH}=\mathrm{N}), 8.89(\mathrm{~s}, 1 \mathrm{H},-\mathrm{NH})$; ${ }^{13} \mathrm{C} \mathrm{NMR}\left(67.93 \mathrm{MHz}, \mathrm{CDCl}_{3}\right) \delta 55.2\left(2 \mathrm{C},-\mathrm{OCH}_{3}\right), 103.9$, 108.1, 114.0, 114.2, 123.6, 127.3, 131.2, 132.2, 134.3, 141.1, 146.6, 162.3, 168.3 (20C, Ar-C); Anal. Found: C, 73.92; H, 5.35; N, 11.76. Calc. for $\mathrm{C}_{22} \mathrm{H}_{19} \mathrm{~N}_{3} \mathrm{O}_{2}$ : C, 73.93; H, 5.36; N, $11.76 \%$. MS (ESI): $\left(\mathrm{M}^{+}\right)$at $m / z 357$.

N1-[(E)-1-(1-Isoquinolyl)methylidene ]-2-(1H-benzo[d] imidazol-2-yl)aniline (9)

Yield $81 \%$; mp 254-256 ${ }^{\circ} \mathrm{C}$; IR $v_{\max } / \mathrm{cm}^{-1}: 3300,1640$, $1610,1580,1130 ;{ }^{1} \mathrm{H}$ NMR $\left(400 \mathrm{MHz}, \mathrm{CDCl}_{3}\right) \delta 6.83(\mathrm{t}$, $1 \mathrm{H}, \mathrm{Ar}, J 7.4 \mathrm{~Hz}$ ), 7.06-8.21 (m, 13H, Ar), 8.72 (d, 1H, $J$ $5.25 \mathrm{~Hz}), 8.89(\mathrm{~s}, 1 \mathrm{H},-\mathrm{NH}) ;{ }^{13} \mathrm{C} \mathrm{NMR}\left(67.93 \mathrm{MHz}, \mathrm{CDCl}_{3}\right)$ $\delta 114.0$ 114.2, 121.6, 123.4, 125.6, 127.3, 128.8, 132.6, 135.6, 141.8, 146.8, 157.2, 168.4 (23C, Ar-C); Anal. Found: C, 79.25; H, 4.60; N, 16.05. Calc. for $\mathrm{C}_{23} \mathrm{H}_{16} \mathrm{~N}_{4}$ : C, 79.29; H, 4.63 ; N, $16.08 \%$. MS (ESI): $\left(\mathbf{M}^{+}\right)$at $m / z 348$.

N1-[(E)-1-(3-Pyridyl)methylidene $]-2-(1 \mathrm{H}$-benzo [d] imidazol-2-yl)aniline (10)

Yield 79\%; mp 230-232 ${ }^{\circ} \mathrm{C}$; IR $v_{\max } / \mathrm{cm}^{-1}: 3300,1640$, $1610,1585,1130 ;{ }^{1} \mathrm{H}$ NMR $\left(400 \mathrm{MHz}, \mathrm{CDCl}_{3}\right) \delta 6.82(\mathrm{t}$, $1 \mathrm{H}, \mathrm{Ar}, J 7.4 \mathrm{~Hz}$ ), 7.05-7.48 (m, 6H, Ar), 7.63 (d, 1H, Ar, J 7.3 Hz), 7.75-8.62 (m, 4H, Ar), 8.65 (s, 1H, Ar), 8.89 (s, $1 \mathrm{H},-\mathrm{NH}) ;{ }^{13} \mathrm{C}$ NMR $\left(67.93 \mathrm{MHz}, \mathrm{CDCl}_{3}\right) \delta 113.4,114.1$, $121.5,123.4,126.3,128.3,130.3,136.5,141.8,143,6$, 146.5, 151.6, 152.8, 165.6 (19 C, Ar-C); Anal. Found: C, 76.50; H, 4.72; N, 18.75. Calc. for $\mathrm{C}_{19} \mathrm{H}_{14} \mathrm{~N}_{4}: \mathrm{C}, 76.49 ; \mathrm{H}$, 4.73; N, 18.78\%. MS (ESI): $\left(\mathrm{M}^{+}\right)$at $m / z 298$. 


\section{2-Benzo[4,5]imidazo[1,2-c]quinazolin-6-ylphenol (11)}

Yield 82\%; mp 300-302 ${ }^{\circ} \mathrm{C}$; IR $v_{\max } / \mathrm{cm}^{-1}$ : 3425, 1621, 1585, 1529, 1457, 1380, 773, 741, 732; ${ }^{1} \mathrm{H}$ NMR (400 MHz, DMSO-d $)_{6} \delta 6.65(\mathrm{~d}, 1 \mathrm{H}, \mathrm{Ar}, J 8.2 \mathrm{~Hz}), 6.81(\mathrm{~d}$, $1 \mathrm{H}, \mathrm{Ar}, J 8.4 \mathrm{~Hz}$ ), 6.83 (t, 1H, Ar, J 7.4 Hz), 7.15-7.85 (m, $8 \mathrm{H}, \mathrm{Ar}), 8.75$ (dd, 1H, J 6.9, $2.5 \mathrm{~Hz}), 10.29$ (s, 1H, -OH); ${ }^{13} \mathrm{C}$ NMR $\left(67.93 \mathrm{MHz}\right.$, DMSO-d $\left.\mathrm{d}_{6}\right) \delta 112.4,116.7,120.3$, $121.5,122.4,125.8,129.3,131.5,132.7,139.2,143.6$, 152.5, 159.2, 161.4 (20 C, Ar-C); Anal. Found: C, 77.18; $\mathrm{H}, 4.19 ; \mathrm{N}, 13.51$. Calc. for $\mathrm{C}_{20} \mathrm{H}_{13} \mathrm{~N}_{3} \mathrm{O}: \mathrm{C}, 77.16 ; \mathrm{H}, 4.21$; N, $13.50 \%$. MS (ESI): $\left(\mathrm{M}^{+}\right)$at $m / z 311$.

\section{2-Benzo[4,5]imidazo[1,2-c]quinazolin-6-yl-4- bromophenol (12)}

Yield 75\%; mp 330-332 ${ }^{\circ} \mathrm{C}$; IR $v_{\max } / \mathrm{cm}^{-1}: 3425,1621$, 1610, 1524, 1459, 1378, 775, 744, 739; ${ }^{1} \mathrm{H}$ NMR (400 MHz, DMSO-d $)_{6} \delta 6.65(\mathrm{~d}, 1 \mathrm{H}, \mathrm{Ar}, J 8.2 \mathrm{~Hz}), 6.81(\mathrm{~d}$, $1 \mathrm{H}, \mathrm{Ar}, J 8.4 \mathrm{~Hz}), 6.82(\mathrm{t}, 1 \mathrm{H}, \mathrm{Ar}, J 7.4 \mathrm{~Hz}), 7.15-7.56$ (m, 6H, Ar), 7.75 (s, 1H, Ar), 8.75 (dd, 1H, J 6.9, 2.5 Hz), 10.30 (s, $1 \mathrm{H},-\mathrm{OH}) ;{ }^{13} \mathrm{C}$ NMR $\left(67.93 \mathrm{MHz}\right.$, DMSO$\left._{6}\right) \delta$ $111.4,118.2,120.1,121.5,122.3,125.8,130.7,131.5$, 132.6, 133.2, 145.6, 146.5, 152.8, 154.5, 161.2 (20 C, Ar-C); Anal. Found: C, 61.55; H, 3.12; N, 10.75. Calc. for $\mathrm{C}_{20} \mathrm{H}_{12} \mathrm{BrN}_{3} \mathrm{O}: \mathrm{C}, 61.56 ; \mathrm{H}, 3.10 ; \mathrm{N}, 10.77 \%$. MS (ESI): at $\mathrm{m} / \mathrm{z}\left(\mathbf{M}^{+}\right) 389,\left(\mathbf{M}^{+2}\right) 391$.

\section{2-Benzo[4,5]imidazo[1,2-c]quinazolin-6-yl-4-nitrophenol} (13)

Yield 76\%; mp 241-243 ${ }^{\circ} \mathrm{C}$; IR $v_{\max } / \mathrm{cm}^{-1}: 3425,1640$, 1605, 1580, 1520, 1459, 1385, 851, 775, 745, 749, 690; ${ }^{1} \mathrm{H}$ NMR (400 MHz, DMSO-d $) ~ \delta 6.64$ (d, 1H, Ar, J 8.2 Hz), 6.82 (d, 1H, Ar, J 8.4 Hz), 6.83 (t, 1H, Ar, J 7.4 Hz), 7.218.15 (m, 6H, Ar), 8.45 (s,1H,Ar), 8.74 (dd, 1H, J 6.9, 2.5 $\mathrm{Hz}), 10.29$ (s, 1H, -OH); ${ }^{13} \mathrm{C}$ NMR (67.93 MHz, DMSO-d 6 ) $\delta 112.4,118.3,120.6,121.7,124.8,125.4,126.8,130.7$, 132.3, 138.4, 143.6, 145.4, 152.1, 163.2, 164.5 (20C, Ar-C); Anal. Found: C, 67.42; H, 3.40N, 15.71. Calc. for $\mathrm{C}_{20} \mathrm{H}_{12} \mathrm{~N}_{4} \mathrm{O}_{3}: \mathrm{C}, 67.41 ; \mathrm{H}, 3.39 \mathrm{~N}, 15.72 \%$. MS (ESI): $\left(\mathrm{M}^{+}\right)$ at $\mathrm{m} / \mathrm{z} 356$.

2-Benzo[4,5]imidazo[1,2-c]quinazolin-6-yl-4methoxyphenol (14)

Yield 81\%; mp 300-302 ${ }^{\circ} \mathrm{C}$; IR $v_{\max } / \mathrm{cm}^{-1}: 3425,1638$, $1615,1575,1465,1380,1245,1038,770,742,739$; ${ }^{1} \mathrm{H}$ NMR (400 MHz, DMSO-d $\left.{ }_{6}\right) \delta 3.91$ (s, 3H, Ar- $\mathrm{OCH}_{3}$ ), 6.65 (d, 1H, Ar, J 8.2 Hz), 6.82 (d, 1H, Ar, J 8.4 Hz), 6.83 (t, 1H, Ar, J 7.4 Hz), 6.98-7.53 (m, 7H, Ar), $8.76(\mathrm{dd}, 1 \mathrm{H}$, $J$ 6.9, $2.5 \mathrm{~Hz}), 10.29(\mathrm{~s}, 1 \mathrm{H},-\mathrm{OH}) ;{ }^{13} \mathrm{C}$ NMR $(67.93 \mathrm{MHz}$, DMSO-d $\left.{ }_{6}\right) \delta 56.3$ (1C, -OCH3), 112.3, 119.6, 121.7, 122.7, $124.8,127.8,130.7,131.2,137.2,143.6,152.2,155.6$, 160.3 (20C, Ar-C); Anal. Found: C, 73.85; H, 4.41; N,
12.30. Calc. for $\mathrm{C}_{21} \mathrm{H}_{15} \mathrm{~N}_{3} \mathrm{O}_{2}: \mathrm{C}, 73.89 ; \mathrm{H}, 4.43 ; \mathrm{N}, 12.31 \%$. MS (ESI): (M+) at $m / z 341$.

3-Benzo[4,5]imidazo[1,2-c]quinazolin-6-ylbenzoic acid (15)

Yield 75\%; mp 238-240 ${ }^{\circ} \mathrm{C}$; IR $v_{\max } / \mathrm{cm}^{-1}: 3535,1685$, 1621, 1585, 1529, 1457, 1380, 773, 741, 732; ${ }^{1} \mathrm{H}$ NMR $\left(400 \mathrm{MHz}, \mathrm{DMSO}_{-} \mathrm{d}_{6}\right) \delta 6.64(\mathrm{~d}, 1 \mathrm{H}, \mathrm{Ar}, J 8.2 \mathrm{~Hz}), 6.82$ (d, $1 \mathrm{H}, \mathrm{Ar}, J 8.4 \mathrm{~Hz}), 6.83$ (t, 1H, Ar, J 7.4 Hz), 7.21-8.31 (m, 7H, Ar), 8.63 (s, 1H, Ar), 8.75 (dd, 1H, J 6.9, 2.5 Hz), 11.34 (s, $1 \mathrm{H},-\mathrm{COOH}) ;{ }^{13} \mathrm{C}$ NMR (67.93 MHz, DMSO-d $)$ $\delta$ 111.6, 114.6, 120.9, 122.8, 124.6, 126.3, 129.7, 131.8, 132.5, 142.6, 143.1, 152.1, 157.8, 167.2 (21C, Ar-C); Anal. Found: C, 74.31; H, 3.85; N, 12.39. Calc. for $\mathrm{C}_{21} \mathrm{H}_{13} \mathrm{~N}_{3} \mathrm{O}_{2}$ : C, 74.33; H, 3.86; N, 12.38\%. MS (ESI): $\left(\mathrm{M}^{+}\right)$at $m / 2339$.

3-Benzo[4,5]imidazo[1,2-c]quinazolin-6-yl-4hydroxybenzoic acid (16)

Yield 78\%; mp 342-344 ${ }^{\circ} \mathrm{C}$; IR $v_{\max } / \mathrm{cm}^{-1}: 3535,3425$, 1680, 1621, 1585, 1529, 1457, 1388, 773, 740, 738; ${ }^{1} \mathrm{H}$ NMR (400 MHz, DMSO-d $)$ ) $\delta 6.65$ (d, 1H, Ar, J 8.2 $\mathrm{Hz}), 6.81$ (d, 1H, Ar, J $8.4 \mathrm{~Hz}), 6.83$ (t, 1H, Ar, J 7.4 Hz), 7.20-8.15 (m, 6H, Ar), 8.49 (s, 1H, Ar), 8.75 (dd, 1H, $J$ 6.9, $2.5 \mathrm{~Hz}), 10.21$ (s, 1H, - $\mathrm{OH}), 11.30(\mathrm{~s}, 1 \mathrm{H},-\mathrm{COOH})$; ${ }^{13} \mathrm{C}$ NMR (67.93 MHz, DMSO-d $) \delta 112.6,117.7,120.5$, $121.7,122.5,128.7,131.8,135.5,143.5,143.2,152.5$, 161.3, 162.8, 165.2 (21C, Ar-C); Anal. Found: C, 70.95; $\mathrm{H}, 3.70 ; \mathrm{N}, 11.80$. Calc. for $\mathrm{C}_{21} \mathrm{H}_{13} \mathrm{~N}_{3} \mathrm{O}_{3}: \mathrm{C}, 70.98 ; \mathrm{H}, 3.69$; N, $11.82 \%$. MS (ESI): $\left(\mathbf{M}^{+}\right)$at $m / z, 355$.

4-Benzo[4,5]imidazo[1,2-c]quinazolin-6-yl-2,6dimethylphenol (17)

Yield 71\%; mp 208-210 ${ }^{\circ} \mathrm{C}$; IR $v_{\max } / \mathrm{cm}^{-1}: 3425,2958$, 1680, 1621, 1585, 1529, 1457, 1388, 773, 741, 739; ${ }^{1} \mathrm{H}$ NMR (400 MHz, DMSO-d $) \delta 2.31$ (s, 6H, - $\mathrm{CH}_{3}$ ), 6.64 (d, 1H, Ar, J $8.2 \mathrm{~Hz}), 6.82$ (d, 1H, Ar, J $8.4 \mathrm{~Hz}), 6.83$ (t, $1 \mathrm{H}, \mathrm{Ar}, J 7.4 \mathrm{~Hz}$ ), 7.20-7.53 (m, 6H, Ar), 8.74 (dd, 1H, $J$ 6.9, $2.5 \mathrm{~Hz}), 10.21(\mathrm{~s}, 1 \mathrm{H},-\mathrm{OH}) ;{ }^{13} \mathrm{C}$ NMR $(67.93 \mathrm{MHz}$, DMSO-d $\left.{ }_{6}\right) \delta 15.6$ (2C, -CH3), 112.8, 114.5, 121.9, 122.4, 124.6, 126.5, 128.7, 133.5, 145.1, 151.1, 152.5, 158.2, (20C, Ar-C); Anal. Found: C, 77.86; H, 5.01; N, 12.35. Calc. for $\mathrm{C}_{22} \mathrm{H}_{17} \mathrm{~N}_{3} \mathrm{O}: \mathrm{C}, 77.86 ; \mathrm{H}, 5.05 ; \mathrm{N}, 12.38 \%$. MS (ESI): $\left(\mathrm{M}^{+}\right)$at $m / z 339$.

6-(3,5-Dimethoxyphenyl)benzo[4,5]imidazo[1,2-c] quinazoline (18)

Yield 75\%; mp 235-237 ${ }^{\circ} \mathrm{C}$; IR $v_{\max } / \mathrm{cm}^{-1}: 1645,1605$, $1528,1456,1246,1380,1038,773,741,732 ;{ }^{1} \mathrm{H}$ NMR (400 MHz, DMSO-d $\left.{ }_{6}\right) \delta 3.90$ (s, 6H, - $-\mathrm{OCH}_{3}$ ), 6.54 (s, 1H, Ar), $6.65(\mathrm{~d}, 1 \mathrm{H}, \mathrm{Ar}, J 8.2 \mathrm{~Hz}), 6.81(\mathrm{~d}, 1 \mathrm{H}, \mathrm{Ar}, J 8.4 \mathrm{~Hz}), 6.83$ (t, 1H, Ar, J 7.4 Hz), 7.20-7.51 (m, 4H, Ar), 7.68 (s, 2H, 
Ar), $8.75(\mathrm{dd}, 1 \mathrm{H}, J 6.9,2.5 \mathrm{~Hz}) ;{ }^{13} \mathrm{C} \mathrm{NMR}(67.93 \mathrm{MHz}$, DMSO-d $\mathrm{d}_{6} \delta 55.4\left(2 \mathrm{C},-\mathrm{OCH}_{3}\right), 103.5,104.7,112.3$, 120.3, 124.3, 126.9, 131.3, 133.4, 141.2, 143.8, 152.2, 155.2, 165.2 (20C, Ar-C); Anal. Found: C, 74.34; H, 4.83; $\mathrm{N}, 11.80$. Calc. for $\mathrm{C}_{22} \mathrm{H}_{17} \mathrm{~N}_{3} \mathrm{O}_{2}: \mathrm{C}, 74.35 ; \mathrm{H}, 4.82$; N, $11.82 \%$. MS (ESI): $\left(\mathrm{M}^{+}\right)^{\text {at }} \mathrm{m} / \mathrm{z} 355$.

6-(1-Isoquinolyl)benzo[4,5]imidazo[1,2-c]quinazoline (19)

Yield 72\%; mp 274-276 ${ }^{\circ} \mathrm{C}$; IR $v_{\max } / \mathrm{cm}^{-1}: 1631,1610$, $1585,1529,1457,1380,773,741,732$; ${ }^{1} \mathrm{H}$ NMR (400 MHz, DMSO-d 6 ) $\delta 6.64(\mathrm{~d}, 1 \mathrm{H}, \mathrm{Ar}, J 8.2 \mathrm{~Hz}), 6.82(\mathrm{~d}, 1 \mathrm{H}$, Ar, J 8.4 Hz), 6.83 (t, 1H, Ar, J 7.4 Hz), 7.21-8.51 (m, 9H, Ar), $8.72(\mathrm{~d}, 1 \mathrm{H}, J 5.25 \mathrm{~Hz}), 8.74(\mathrm{dd}, 1 \mathrm{H}, J 6.9,2.5 \mathrm{~Hz})$; ${ }^{13} \mathrm{C}$ NMR $(67.93 \mathrm{MHz}$, DMSO-d 6 ) $\delta 114.2,116.5,120.3$, 121.5, 123.3, 126.6, 133.3, 136.2, 138.4, 141.2, 145.2, 152.2, 153.1, 153.8 (23C, Ar-C); Anal. Found: C, 79.72; $\mathrm{H}, 4.05 ; \mathrm{N}, 16.18$. Calc. for $\mathrm{C}_{23} \mathrm{H}_{14} \mathrm{~N}_{4}$ : C, 79.75; H, 4.07; N, $16.17 \%$. MS (ESI): $\left(\mathbf{M}^{+}\right)$at $m / z, 346$.

6-(3-Pyridyl)benzo[4,5]imidazo[1,2-c]quinazoline (20)

Yield 73\%; mp 244-246 ${ }^{\circ} \mathrm{C}$; IRv $v_{\max } / \mathrm{cm}^{-1}: 1635,1610$, 1580, 1530, 1457, 1380, 775, 742, 731; ${ }^{1} \mathrm{H}$ NMR (400 MHz, DMSO-d $\left.\mathrm{d}_{6}\right) \delta 6.65(\mathrm{~d}, 1 \mathrm{H}, \mathrm{Ar}, J 8.2 \mathrm{~Hz}), 6.82(\mathrm{~d}$, $1 \mathrm{H}, \mathrm{Ar}, J 8.4 \mathrm{~Hz}), 6.83$ (t, 1H, Ar, J 7.4 Hz), 7.11-8.12 (m, 7H, Ar), 8.61 (dd, 1H, J 6.9, 2.5 Hz) 8.95 (s, 1H, Ar); ${ }^{13} \mathrm{C}$ NMR $(67.93 \mathrm{MHz}$, DMSO-d 6 ) $\delta 113.5,119.6,120.7$, 123.3, 126.2, 130.3, 132.6, 137.2, 142.2, 146.7, 149.4, 150.1, 152.1 (19C, Ar-C); Anal. Found: C, 77.01; H, 4.05; $\mathrm{N}, 18.90$. Calc. for $\mathrm{C}_{19} \mathrm{H}_{12} \mathrm{~N}_{4}: \mathrm{C}, 77.01 ; \mathrm{H}, 4.08 ; \mathrm{N}, 18.91 \%$. MS (ESI): (M+) at $m / z 296$.

\section{Supplementary Information}

Spectral data of compounds are available free of charge at http://jbcs.sbq.org.br, as pdf file.

\section{References}

1. Polshettiwar, V.; Varma, R. S.; Curr. Opin. Drug Discovery Dev. 2007, 10, 723.

2. Padwa, A.; Bur, S. K.; Tetrahedron 2007, 63, 5341.

3. D’Souza, D. M.; Muller, T. J.; Chem. Soc. Rev. 2007, 36, 1095.

4. Sahu, S. K.; Afzal Azam, Md.; Banerjee, M.; Acharrya, S.; Beheraa, C. C.; Si , S.; J. Braz. Chem. Soc. 2008, 19, 963.

5. Saeed, A.; Abbas, N.; Florke, U.; J. Braz. Chem. Soc. 2007, 18, 559.

6. Cerchiaro, G.; Ferreira, A. M. C.; J. Braz. Chem. Soc. 2006, 17, 1473.

7. DeSimone, R. W.; Currie, K. S.; Mitchell, S. A.; Darrow, J. W.; Pippin, D. A.; Comb. Chem. High Throughput Screen 2004, 7, 473.
8. Zhang, Y.; Chen, Z.; Lou, Y.; Yu, Y.; Eur. J. Med. Chem. 2009, $44,448$.

9. Ishida, T.; Suzuki, T.; Hirashima, S.; Mizutani, K.; Yoshida, A.; Ando, I.; Ikeda, S.; Adachi, T.; Hashimoto, H.; Bioorg. Med. Chem. Lett. 2006, 16, 1859.

10. Herget, T.; Freitag, M.; Morbitzer, M.; Kupfer, R.; Stamminger, T.; Marschall, M.; Antimicrob. Agents Chemother. 2004, 48, 4154.

11. Hranjec, M.; Karminski-Zamola G.; Chemistry in Industry 2008 , 57, 299.

12. Chan, K. P.; Yang, H.; Hay, A. S.; J. Polymer Sci. 1996, 34, 1923.

13. Kumar, A.; Rajput, C. S.; Eur. J. Med. Chem. 2009, 44, 83.

14. Spasov, A. A.; Yozhitsa, I. N.; Bugaeva, L. I.; Anisimova, V. A.; Pharm. Chem. J. 1999, 33, 232.

15. Alexandre, F.; Berecibar, A.; Wrigglesworth, R.; Besson, T.; Tetrahedron 2003, 59, 1413.

16. Alagarsamy, V.; Giridhar, R.; Yadav, M. R.; Revathi, R.; Ruckmani, K.; Clercq, E. D.; Indian J. Pharm. Sci. 2006, 68, 532.

17. Jindal, D. P.; Bhatti, R. S.; Ahlawat, S.; Gupta, R.; Eur. J. Med. Chem. 2002, 37, 419.

18. Sircar, J. C.; Capiris, T.; Kesten, S. J.; Herzig, D. J.; J. Med. Chem. 1981, 24, 735.

19. Zhang, Y.; Chen, Z.; Lou, Y.; Yu, Y.; Eur. J. Med. Chem. 2009, $44,448$.

20. Rashood, S. T. A.; Aboldahab, I. A.; Nagi, M. N.; Abouzeid, L. A.; Aziz, A. A. M. A.; Hamide, S. G. A.; Youssef, K. M.; Obaid, A. M. A.; Subbagh, H. I. E.; Bioorg. Med. Chem. 2006, 14,8608 .

21. Hennequin, L. F.; Allen, J.; Breed, J.; Curwen, J.; Fennell, M.; Green, T. P.; Brempt, C. L.; Morgentin, R.; Norman, R. A.; Oliver, A.; Otterbein, L.; Ple, P. A.; Warin, N.; Costello, G.; J. Med. Chem. 2006, 49, 6465.

22. Hori, M.; Iemura, R.; Hara, H.; Ozaki, A.; Sukamoto, T.; Ohtaka, H.; Chem. Pharm. Bull. 1990, 38, 681.

23. Vostrova, L. N.; Voronina, T. A.; Karaseva, T. L.; Gernega, S. A.; Ivanov, É. I.; Kirichenko, A. M.; Totrova, M. Yu.; Pharm. Chem. J. 1986, 20, 404.

24. Gupta, D. P.; Ahmad, S.; Kumar, A.; Shankar, K.; Indian J. Chem. 1998, 27B, 1060.

25. Alagarsamy, V.; Rajasolomon, V.; Meena, R.; Ramseshu, K.V.; Biol. Pharm. Bull. 2005, 28, 1091.

26. Guan, J.; Zhang, Q.; Neil, M.; Obaldia, N.; Ager, A.; Gerena, L.; Lin, A.; Antimicrob. Agents Chemother. 2005, 49, 4928.

27. Bedi, P. M. S.; Kumar, V.; Mahajan, M. P.; Bioorg. Med. Chem. Lett. 2004, 14, 5211.

28. Lamazzi, C.; Leonce, S.; Pfeiffer, B.; Renard, P.; Guillaumet, G.; Rees, C. W.; Besson, T.; Bioorg. Med. Chem. Lett. 2000, 10, 2183. 
29. Insuasty, B. A.; Torres, H.; Quiroga, J.; Abonia, R.; Rodriguez, R.; Nogueras, M.; Sanchez, A.; Saitz, C.; Alvarez, S. L.; Zacchino, S. A.; J. Chil. Chem. Soc. 2006, 51, 927.

30. Galarcei, G. D.; Foncea, R. E.; Edwards, A. M.; Pessoamahana, H.; Mahana, C. D. P.; Ebenspergeri, R. A.; Biol. Res. 2008, 41, 43.

31. Hein, D. W.; Alheim, R. J.; Leavitt, J. J.; J. Am. Chem. Soc. 1957, 79, 427.

32. Davis, M.; Mann, F. G.; J. Chem. Soc. 1962, 945.

33. Pareek, S.; Vyas, S.; Seth, G.; Vyas, P.C.; Heteroat. Chem. 2008 , 19, 154.

34. Fadda, A. A.; Refat, H. M.; Zaki, M. E. A.; Monir, E.; Synth. Commun. 2001, 31, 3537.
35. Amudha, P.; Akilan, P.; Kandaswamy, M.; Polyhedron 1999, $18,1355$.

36. V. V.; Korshak, A. L.; Rusanov, T. G.; Iremashvili, L. K.; Plieva, T. V.; Lekae, Die Makromolekulare Chemie 1973, 176, 1271.

37. Jung, H. J.; Singh, N.; Jang, D. O.; Tetrahedron Lett. 2008, 49, 2960.

38. Seely H. W.; Vandemark, P. J.; Microbes in Action: A Laboratory Manual of Microbiology, $3^{\text {rd }}$ ed., W. H. Freeman: San Francisco, USA, 1981.

39. Malue, M.; Bastide, J. M.; Biancard, A.; Int. J. Antimicrob. Agents 2005, 25, 321.
Received: April 15, 2009

Web Release Date: October 9, 2009 


\title{
Synthesis and Antimicrobial Activities of a New Class of 6-Arylbenzimidazo[1,2-c]quinazolines
}

\author{
Rondla Rohini, ${ }^{a}$ Kanne Shanker, ${ }^{a}$ P. Muralidhar Reddy ${ }^{b}$ and Vadde Ravinder ${ }^{a *}$ \\ ${ }^{a}$ Department of Chemistry, Kakatiya University, Warangal-506 009, A.P., India \\ ${ }^{b}$ Department of Chemistry, National Dong Hwa University, Hualien, Taiwan
}

\section{Antibacterial activity}

Antibacterial testing was performed by cup plate method. ${ }^{38}$ Nutrient broth was prepared by dissolving peptone $(0.5 \%)$, yeast extract $(0.15 \%)$, beef extract $(0.15 \%)$, sodium chloride $(0.36 \%)$, and monopotassium phosphate $(0.13 \%)$ in distilled water $(100 \mathrm{~mL})$. The $\mathrm{pH}$ of the solution was adjusted to 7.2 by adding sodium hydroxide solution (4\%) and the resulting solution was autoclaved for $20 \mathrm{~min}$ at 15 psi. One day prior to the experiment, the cultures against Staphylococcus aureus, Bacillus subtilis, Streptococcus pyogenes, Salmonella typhimurium, Escherichia coli and Klebsiella pneumonia were inoculated in nutrient broth (inoculation medium) and incubated overnight at $37^{\circ} \mathrm{C}$. Nutrient agar medium was prepared by dissolving peptone $(1 \%)$, yeast extract $(0.6 \%)$, beef extract $(0.5 \%)$, and sodium chloride $(0.5 \%)$ in distilled water. The $\mathrm{pH}$ of the solution was adjusted to 7.2 by adding $4 \%$ aqueous sodium hydroxide solution. Agar (2.4\%) was then added and the whole solution was autoclaved for $20 \mathrm{~min}$ at $15 \mathrm{psi}$. Preliminary screening for ten quinazolines was performed at fixed concentrations of $1000 \mu \mathrm{g} \mathrm{mL} \mathrm{mL}^{-1}$. Inoculation medium containing 24-hours grown culture was added aseptically to the nutrient medium and mixed thoroughly to get the uniform distribution. This solution was poured ( $25 \mathrm{~mL}$ in each dish) into Petri dishes and then allowed to attain room temperature. Thereafter, six millimeter wide bores were made on the agar using a borer. The solutions of test samples were added into each of the bores using a sterile tip with micropipette. Ampicillin was used as the standard and DMSO as the solvent control. The test samples and the standard were tested at a concentration of
$1000 \mu \mathrm{g} \mathrm{mL}^{-1}$. The plates were allowed to stand for $1 \mathrm{~h}$ in order to facilitate the diffusion of the drug solution. Then the plates were incubated at $37^{\circ} \mathrm{C}$ for $48 \mathrm{~h}$. The zones of inhibition against all the microorganisms were measured in millimeters.

\section{Antifungal activity}

The antifungal activity of quinazoline compounds were tested against the pathogenic fungi Aspergillus niger, Candida albicans, Trichoderma viridae by cup-plate method. ${ }^{38}$ Nutrient agar medium was prepared by the same method as explained under evaluation of antibacterial activity. One and half day prior to the experiment, the fungal cultures of Aspergillus niger, Candida albicans and Trichoderma viridae prepared in the inoculation medium were incubated at $37^{\circ} \mathrm{C}$ for $36 \mathrm{~h}$. The fungal medium was prepared by dissolving peptone $(0.5 \%)$, sodium chloride $(0.36 \%)$, monopotassium phosphate $(0.13 \%)$, and glucose $(2 \%)$ in distilled water $(100 \mathrm{~mL})$. The $\mathrm{pH}$ of the solution was adjusted to 7.2 by adding sodium hydroxide solution (4\%) and the resulting solution was autoclaved for $20 \mathrm{~min}$ at $15 \mathrm{psi}$. This was cooled to $45-50{ }^{\circ} \mathrm{C}$ with gentle shaking. One and half day, grown cultures were added aseptically to this medium and mixed thoroughly to get uniform distribution. The solutions of the test samples and standard were evaluated for antifungal activity by cup-plate method at a concentration of $1000 \mu \mathrm{g}$. The zone of inhibition was measured in millimeter for the particular test sample with each organism at $72 \mathrm{~h}$ interval. Ketoconazole was used as the standard.

*e-mail: ravichemku@ rediffmail.com 


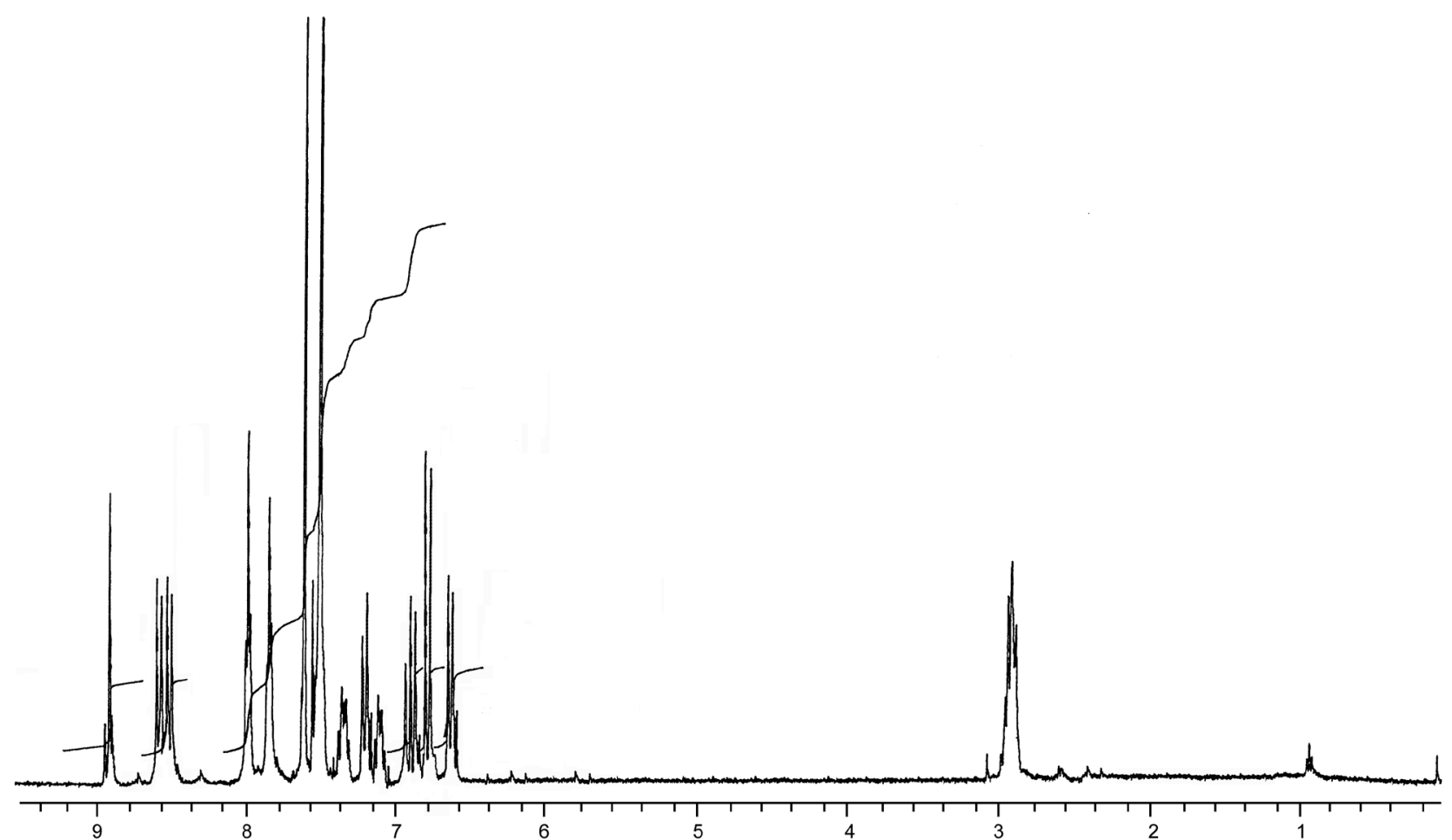

Figure S1. ${ }^{1} \mathrm{H}$ NMR spectrum of 6-(3-pyridyl)benzo[4,5]imidazo[1,2-c]quinazoline (20).

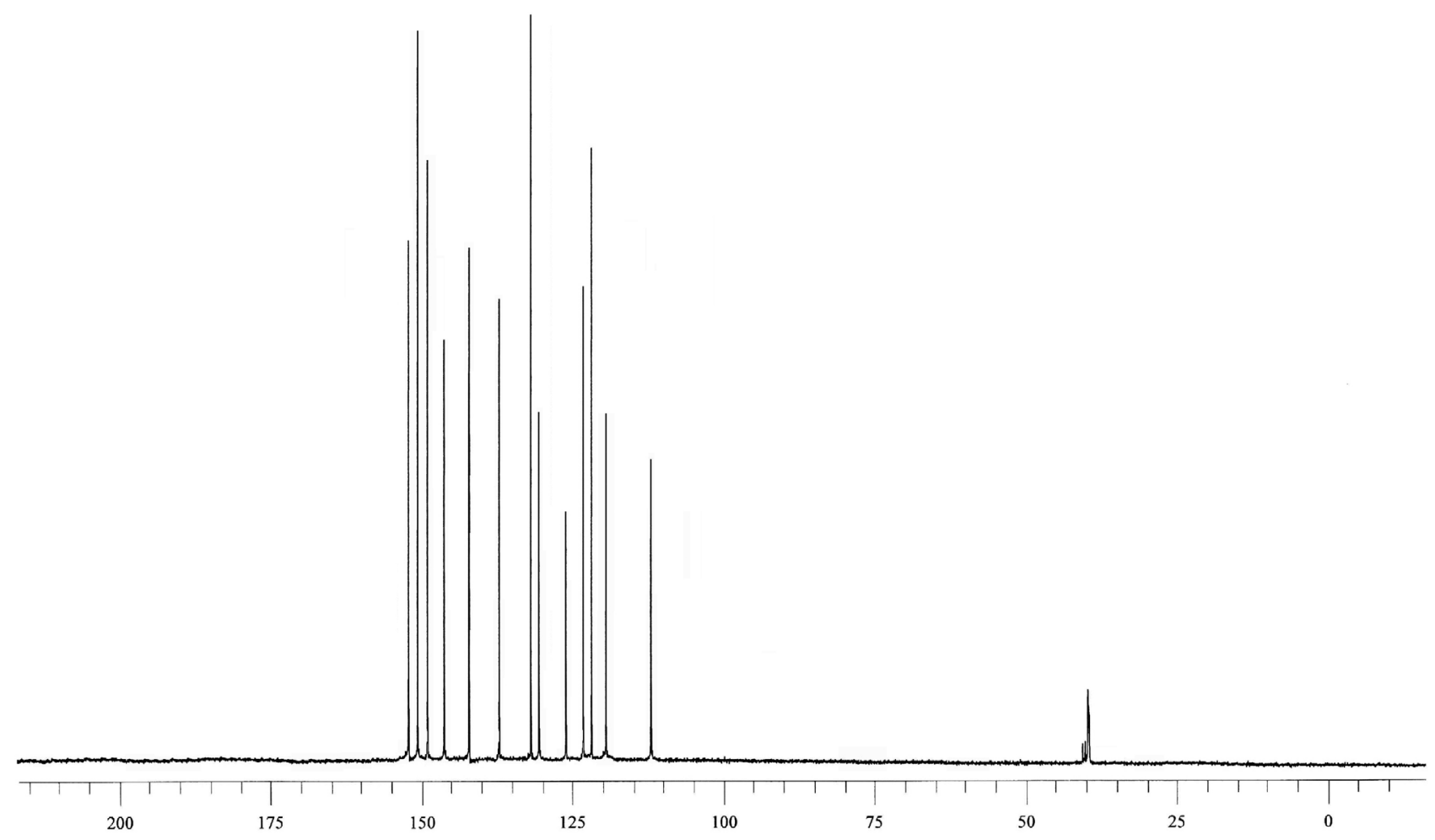

Figure S2. ${ }^{13} \mathrm{C}$ NMR spectrum of 6-(3-pyridyl)benzo[4,5]imidazo[1,2-c]quinazoline (20). 


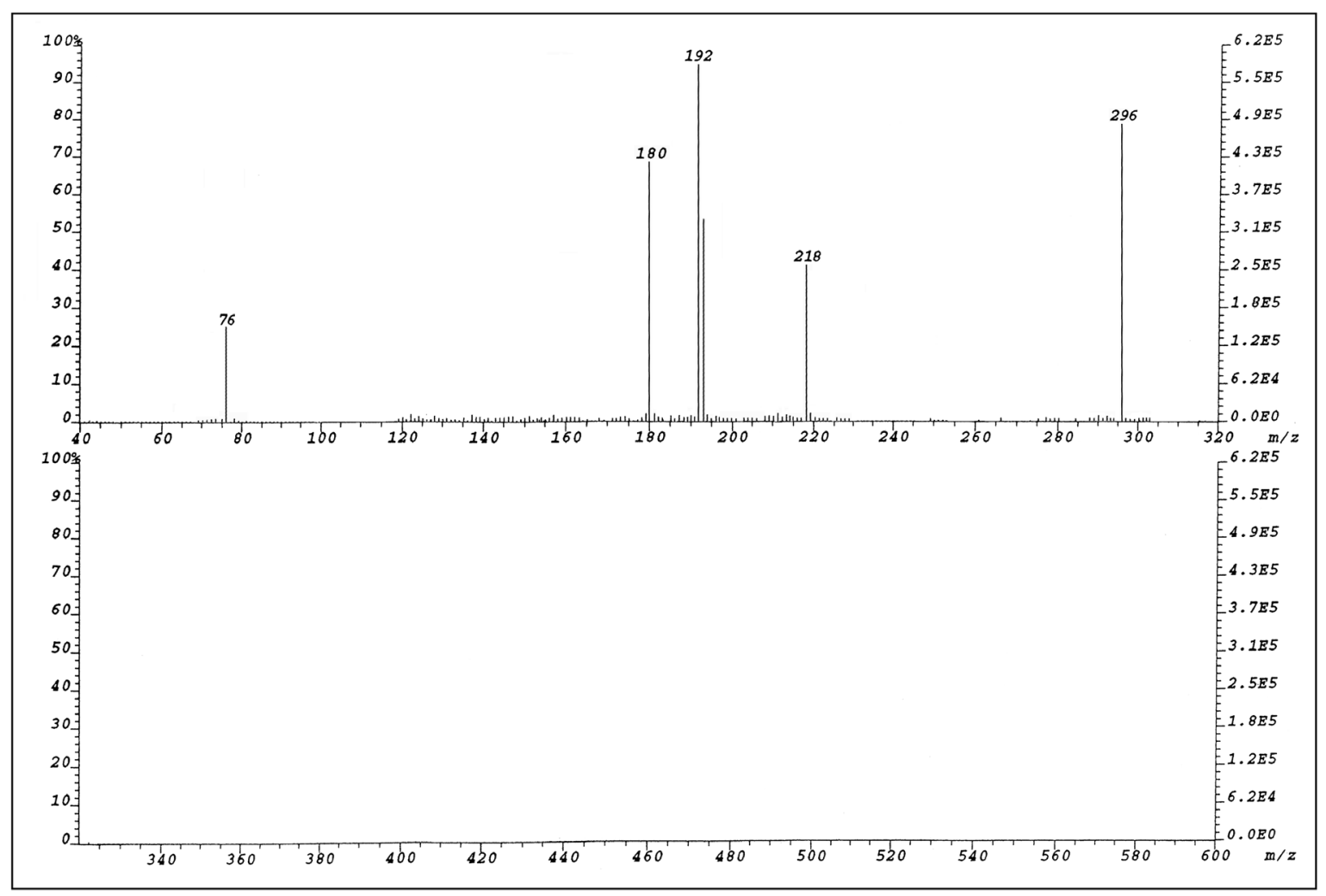

Figure S3. FAB mass spectrum of 6-(3-pyridyl)benzo[4,5]imidazo[1,2-c]quinazoline (20).

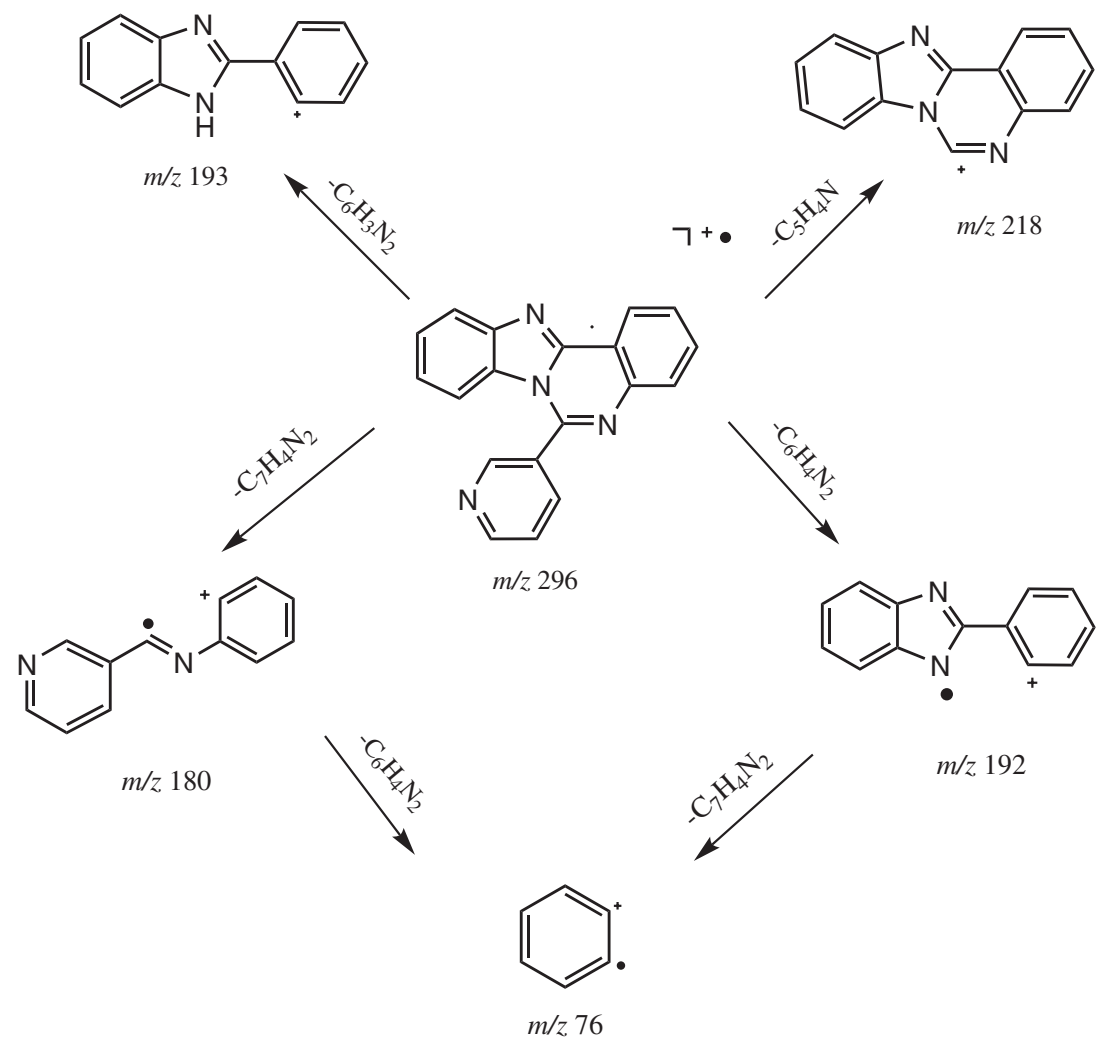

Scheme S1. FAB mass fragmentation pattern of 6-(3-pyridyl)benzo[4,5]imidazo[1,2-c]quinazoline (20). 